\title{
A 3D platform for the morphology modulation of materials: first principles calculations on the thermodynamic stability and surface structure of metal oxides: $\mathrm{Co}_{3} \mathrm{O}_{4}, \alpha-\mathrm{Fe}_{2} \mathrm{O}_{3}$, and $\ln _{2} \mathrm{O}_{3}$
}

\author{
M M Ferrer ${ }^{1}$, A F Gouveia ${ }^{1}$, L Gracia ${ }^{2}$, E Longo ${ }^{3}$ and \\ J Andrés ${ }^{2}$ \\ 1 INCTMN-UFSCar, Universidade Federal de São Carlos, PO Box 676, 13565-905 \\ São Carlos, SP, Brazil \\ 2 Department of Analytical and Physical Chemistry, University Jaume I (UJI), \\ Castelló 12071, Spain \\ 3 INCTMN-UNESP, Universidade Estadual Paulista, PO Box 355, CEP 14801-907 \\ Araraquara, SP, Brazil \\ E-mail: andres@qfa.uji.es
}

Received 16 July 2015, revised 16 November 2015

Accepted for publication 26 November 2015

Published

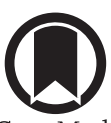

\begin{abstract}
Essentially, the exposed crystal planes of a given material, which primarily determine their morphology, tremendously affect its behavior. First principle calculations, based on the Wulff construction model and broken bonding density index, have been performed to calculate the equilibrium and their transformations for different metal oxides: $\mathrm{Co}_{3} \mathrm{O}_{4}, \alpha-\mathrm{Fe}_{2} \mathrm{O}_{3}$, and $\mathrm{In}_{2} \mathrm{O}_{3}$. Present results point out that starting by surface thermodynamics is a helpful approach to predict and assess the morphology transformations of these materials. These complete set of morphologies may serve as a guide for researchers, when analyzing the images from electron microscopies, to gain further understanding of how to control crystal shape synthetically by tuning the surface chemistry and by controlling the relative values of surface energies.
\end{abstract}

Keywords: morphology, Wulff construction, surface energy, $\mathrm{Co}_{3} \mathrm{O}_{4}, \alpha-\mathrm{Fe}_{2} \mathrm{O}_{3}$, $\mathrm{In}_{2} \mathrm{O}_{3}$ 


\section{Introduction}

A few years ago, McIlroy et al [1] stated: 'Currently, there is a large divide between surface scientists and most catalysis researchers (who make and test new materials), caused by the inability of existing experimental and theoretical techniques to deal with the real-world nanomorphologies. Closing this divide would allow the entire surface science community to be much more effective.' In recent years, there has been such speed and development in this area that this is no longer a valid assessment. The current combination of theory, simulation, and experiment is not only capable of developing new functional materials with predictable and desirable properties, but also enables us to understand the nature of micro and nano-structures with novel morphologies.

Control of the morphology of micro and nanocrystals depends on factors such as the internal structure of the crystal and the external growth conditions. The surface facet energies can be modified by the use of different synthetic methods, reaction times, the nature of surfactants etc. In this sense, the rational design of nanomaterials is one of the holy grails of nanoscience and nanotechnology. The precise regulation and controlled synthesis of specific morphologies is crucial to enhance their performance in practical applications of micro and nanomaterials [2].

Predicting the $3 \mathrm{D}$ morphologies of crystalline materials can be used to guide the analysis of field-emission scanning electron microscopy images of the materials, and could be a very useful tool to design the synthesis of new materials. However, there are many scientific and technological challenges to overcome; in particular, we must understand the relationship between properties and structure.

Since various physical and chemical processes occur at surfaces, an understanding of the surface structure and the factors that affect surfaces is important. The shape of crystals grown under or near equilibrium conditions is governed mainly by surface energies, forming simple shapes with well-defined facets that can achieve minimum surface energy [3]. One method of predicting the morphology of a crystal is to calculate the energies of the different surfaces and these value can be associated to the fraction of surface atoms with unsaturated coordination shells, i.e. the number of under-coordinated surface atoms. The predominant surface will be the most stable surface; but measuring the geometries and energies of the surface facets is extremely challenging. In this context, surface energies are not readily acquired by experiment, and computer modeling and simulation are necessary to obtain these energies, being a powerful tool to explore the morphological mechanism at the atomistic/molecular level.

Theory and simulation in this research area should be further strengthened, which focuses on understanding the morphology, can guide the efficient synthesis of outstanding materials. First principles investigations are well established in the study of the morphology and surface properties of materials, from simple to complex metal oxides [4-27]. There are several insightful reviews that report experimental results and theoretical calculations on the most important aspects that govern crystal shape modulation in semiconductors and in metal nanoparticles [12, 28-31]. Theoretical works, in which surface modification by explicit or implicit solvation/hydration/redox effect are taken into account, can be considered the current state-of-the-art on theoretical methods and computing procedures. In this context, good illustrations have been published, as showed in these recent works: (1) the stabilization effect of surface impurities on the structure of ultrasmall $\mathrm{ZrO}_{2}$ nanoparticles [32], (2) on the basis of theoretical predictions, Yang et al have synthesized uniform anatase $\mathrm{TiO}_{2}$ single crystals with a high percentage of reactive facets [33], (3) theoretical investigations into the structure and surface thermodynamics of the (100) facet of $\mathrm{Co}_{3} \mathrm{O}_{4}$ at various 
redox conditions [34] as well as the morphological control of $\mathrm{Co}_{3} \mathrm{O}_{4}$ to enhace the oxidation of $\mathrm{CO}$ at low tempertaure [35], and (4) the mechanism of morphology transformation of tetragonal phase $\mathrm{LaVO}_{4}$ nanocrystals controlled by surface chemistry: experimental and theoretical insights, in which equilibrium geometries, surface energies, and surface tensions are calculated for selected low-index surfaces of tetragonal $\mathrm{LaVO}_{4}$ under the different surface passivated conditions [24].

Recently, we have determined the morphologies of several metal oxides such as $\mathrm{SnO}_{2}$, $\mathrm{PbMoO}_{4}$, and $\mathrm{CaWO}_{4}$ using ab initio quantum mechanical calculations [15-20]. First principles calculations were also used to study the the effects of surface stability on the morphological transformation of different metals and metal oxides $\left(\mathrm{Ag}\right.$, anatase $\mathrm{TiO}_{2}, \mathrm{BaZrO}_{3}$, and $\alpha-\mathrm{Ag}_{2} \mathrm{WO}_{4}$ ) [36]. Morphological transformations are due to the geometric constraints imposed by the crystal structure and are associated with the relative values of the surface energy of each face. In this context, and we have analyzed theoretical morphology modulation for $\alpha-\mathrm{Ag}_{2} \mathrm{WO}_{4}$ [37], $\mathrm{Ag}_{3} \mathrm{PO}_{4}$ [38] and $\mathrm{Ag}_{2} \mathrm{MoO}_{4}$ [39] materials in order to explain the surface energy changes observed in experimental conditions, and how the knowledge of surface-specific properties can be utilized to design a number of crystal morphologies that may offer improved performance in various applications. It is important to remark that along our calculations specific solvent and/or surfactants interactions or hydration/redox effects on each face are not considered.

The main objective of this work is to show how the values of surface energies, obtained from first principle calculations in vacuo, can be used to obtain possible morphologies under thermodynamic equilibrium conditions for three metal oxides: $\mathrm{Co}_{3} \mathrm{O}_{4}, \alpha-\mathrm{Fe}_{2} \mathrm{O}_{3}$, and $\mathrm{In}_{2} \mathrm{O}_{3}$ as well as to better understand the mechanism of morphological transformation at atomic level. The results of calculations have been compared with the experimental data. It is important to note the following aspects: (i) we have used the values of surface energy from literature, and we are confident that the proposed set of morphologies is not dependent on the calculation level; (ii) the values of surface energies are obtained in vacuo; (iii) from these values we are capable to predict the available morphologies for a crystalline material; (iv) by screening of the relative values of surface energies, a desired morphology can be obtained; (v) an analysis of how the idealized in vacuo surface results can be related to the in situ behavior, and this strategy allow us to find the target and control of crystal morphologies, as well as to rationalize the different channels starting from the ideal morphology.

The whole paper is arranged as follows: (2) a description of theoretical method and computational procedure, (3) the application of the method and the presentation of results, and (4) our main conclusions and perspectives close this letter.

\section{Theoretical method and computational procedure}

From the thermodynamic point of view, the free energy of the crystal facets $\left(E_{\text {surf }}\right)$ determines the equilibrium shape by a classic Wulff construction, which minimizes the total surface free energy at a fixed volume [40]. The Wulff theorem provides a simple relationship between the $E_{\text {surf }}$ of the $(h k l)$ plane and the distance, $r_{h k l}$, in the normal direction from the center of the crystallite. In addition, we have calculated the broken bonding density $\left(D_{\mathrm{b}}\right)$ index proposed by Gao et al [41] $D_{\mathrm{b}}$, the number of bonds broken per area on creation of a new surface calculated from equation (1), where $N_{\mathrm{b}}$ is the number of broken bonds per unit cell area on a particular surface and $A$ is the area of the surface unit cell.

$$
D_{\mathrm{b}}=N_{\mathrm{b}} / A
$$


Table 1. Values of $E_{\text {surf }}$, number of broken bonds, area, and broken bonding density $\left(D_{\mathrm{b}}\right)$ calculated for $\mathrm{Co}_{3} \mathrm{O}_{4}$.

\begin{tabular}{lllll}
\hline \multicolumn{5}{c}{$\mathrm{Co}_{3} \mathrm{O}_{4}$} \\
\hline Surface & $E_{\text {surf }}\left(\mathrm{J} \mathrm{m}^{-2}\right)$ & Broken bonds & Area $\left(\mathrm{nm}^{2}\right)$ & $D_{\mathrm{b}}\left(\mathrm{nm}^{-2}\right)$ \\
\hline$(100)$ & 0.92 & 12 & 0.3258 & 36.83 \\
$(110)$ & 1.31 & 20 & 0.4607 & 43.41 \\
$(111)$ & 2.31 & 15 & 0.2821 & 53.17 \\
$(112)$ & 1.46 & 36 & 0.7980 & 45.11 \\
\hline
\end{tabular}

\section{Results and discussion}

\section{1. $\mathrm{Co}_{3} \mathrm{O}_{4}$}

$\mathrm{Co}_{3} \mathrm{O}_{4}$ is a multifunctional material that has many applications and has received much theoretical and practical investigation [14, 42-45]. $\mathrm{Co}_{3} \mathrm{O}_{4}$ has a face centered cubic spinel structure, crystallizing in space group $F d-3 m$, and has two formula units $(Z=2)$ in the unit cell. Zasada et al [14] obtained the surface energies for the low index faces (100), (11 10), and (111) using calculations on a $\mathrm{Co}_{3} \mathrm{O}_{4}$ slab and compared the Wulff construction for this simulated material with the experimental morphology of $\mathrm{a} \mathrm{Co}_{3} \mathrm{O}_{4}$ nanocrystal. Su et al [46] synthesized single crystalline $\mathrm{Co}_{3} \mathrm{O}_{4}$ nanocrystals with different exposed crystal planes and wide range of morphologies such as cubic, pseudo octahedral, nanosheets, and nanoplatelets, and so on. These authors found a correlation between the reducing charge - discharge overpotential with crystal planes of $\mathrm{Co}_{3} \mathrm{O}_{4}$ and established an order of catalytic activity: $\left(\begin{array}{lll}1 & 1 & 1\end{array}\right)>(110)>(112)>$ (100), and very recently, Liu et al [47] have confirmed the facet-dependent electrocatalytic performance of $\mathrm{Co}_{3} \mathrm{O}_{4}$ for rechargeable $\mathrm{Li}-\mathrm{O}_{2}$ battery.

The Wulff construction for $\mathrm{Co}_{3} \mathrm{O}_{4}$ structure has been obtained from the work of Su et al [46]. Table 1 lists the values of the surface energies obtained by Su et al [46] as well as the broken bonding density $\left(D_{\mathrm{b}}\right)$ of the faces used in the Wulff construction. The $D_{\mathrm{b}}$ values can be directly related to the order of surface stability because higher values represent the presence of a larger quantity of defects on the surface (broken bonds). For the $\mathrm{Co}_{3} \mathrm{O}_{4}$ simulated system, table 1 reveals that the order of stability of the faces is $\left(\begin{array}{lll}1 & 0 & 0\end{array}\right)>\left(\begin{array}{lll}1 & 1 & 0\end{array}\right)>(112)>(111)$.

The complete set of morphologies for $\mathrm{Co}_{3} \mathrm{O}_{4}$ structure has been depiected in figure 1 , in which the transformations can be obtained by changing the ratio bettwen the values of $E_{\text {surf }}$ for each surface. Transformations between the different morphologies are due to the geometric constraints imposed by the crystal structure and are associated with the relative surface energy value of each surface. This interpretation has the advantage that all faces grow from the initial $\mathrm{Co}_{3} \mathrm{O}_{4}$ crystal (ideal) as function of their surface energy value. It is important to note that these images will serve as a guide to better interpret the morphological changes according to the synthetic method used, and so on. In addition, the different degrees of saturation at the surface, and consequently the different $D_{\mathrm{b}}$ values, in the simulated system play an important role in the predicted morphology of the crystal and these differences must be considered when comparing experimental and theoretical results. In a real system, the surfaces can adsorb species present during synthesis, and these adsorbed species will affect the surface energy and, thus, the final morphology, as shown in figure 1. Therefore, several research groups have been reported the synthesis of different morphologies of the $\mathrm{Co}_{3} \mathrm{O}_{4}$ indicated on figure 1, such as cubic (a) [46-49], octahedron (b) [47], and pseudo octahedron (c) [46], in which it is necessary to differ one of the (110)-surface group $\left(E_{\text {surf }}^{(110) *}\right.$ can be $E_{\text {surf }}^{(110)}$ or $E_{\text {surf }}^{(011)}$ or $\left.E_{\text {surf }}^{(101)}\right)$. 


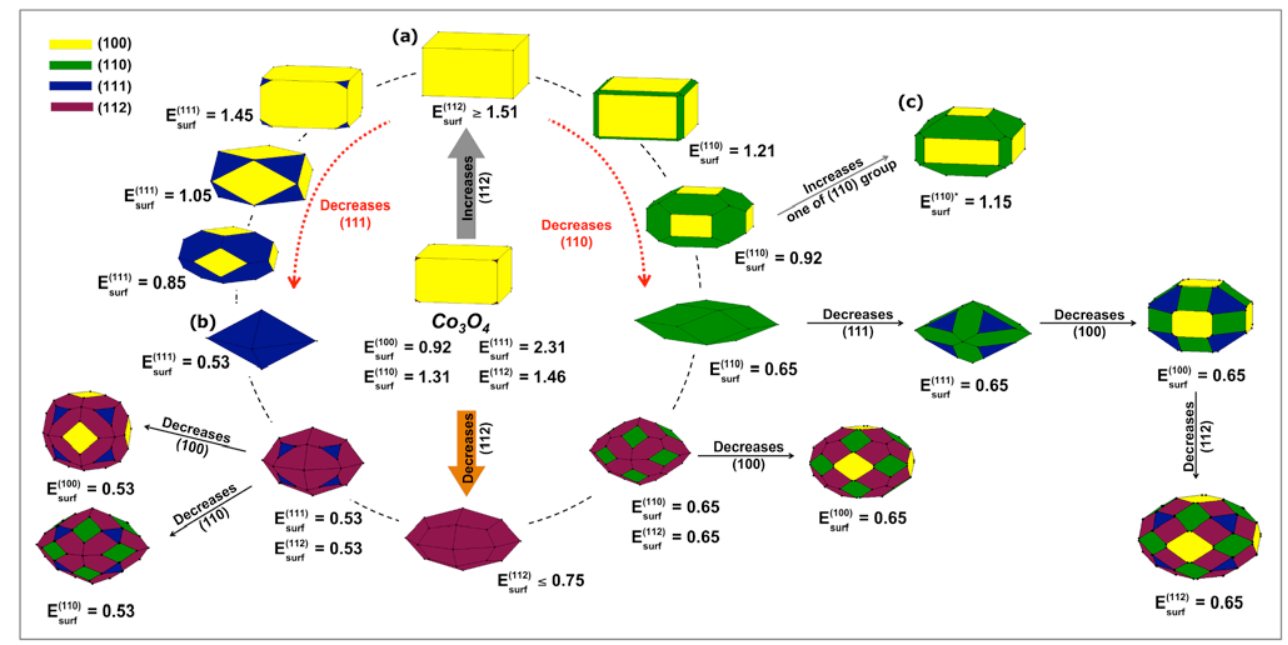

Figure 1. Crystallographic structure and morphologies of $\mathrm{Co}_{3} \mathrm{O}_{4}$ with crystal planes (100), (1 1 10), (1 1 1 1) and (112). Surface energy is in joule per-square meter.

\section{2. $\alpha-\mathrm{Fe}_{2} \mathrm{O}_{3}$}

Iron nanomaterials are used in catalysts and electrodes, as medical imaging contrast agents, adsorbents, and magnetic recording devices. The morphology of individual particles is one of the determining factors in their performance, stability, and in the safety of both engineered nanoparticles as well as natural samples. For example, pseudocube-shaped hematite nanoparticles have a significantly larger permanent magnetization and coercivity than rice-shaped particles [50].

Hematite $\left(\alpha-\mathrm{Fe}_{2} \mathrm{O}_{3}\right)$ also has unique optical and electronic properties and is among the most important materials discussed in literature regarding energy-conversion processes [51-55]. Thus, there is considerable scientific and technological interest in the morphology of iron oxides, as it is demonstrated in various studies, reporting different morphologies synthesized via a template-free hydrothermal route [56], under the influence of $\mathrm{H}_{2} \mathrm{PO}_{4}^{-}$ions [57], prepared by forced hydrolysis of ferric chloride [58], synthesized via an octadecylamine-assisted [59] and via atriphenyl-phosphine-assisted [60] hydrothermal method and with an oriented attachment mechanism controlled by different solvents [61]. Recently, a relationship between surface structure of hematite (001) and the macroscopic charging (zetapotential measurements in electrolyte solutions as a function of $\mathrm{pH}$ ) has been reported [62], and the shape of $\mathrm{Fe}_{3} \mathrm{O}_{4}$ ferroferric oxide nanoparticles synthesized by a coprecipitation method as well as their electrochemical performances has been investigated [63]. Much effort is being directed towards the controlled synthesis of functional nanomaterials in which the shape and size can be engineered.

$\alpha-\mathrm{Fe}_{2} \mathrm{O}_{3}$ crystallizes in the trigonal space group $R-3 c$, and is isostructural with corundum, $\mathrm{Al}_{2} \mathrm{O}_{3}$. It is one of the most thermodynamically stable and abundant phases among all of the iron oxides and oxyhydroxides. Each rhombohedral unit cell contains four Fe atoms, distributed over two cation layers. The spins of the Fe atoms in the layers perpendicular to the [0001] axis are aligned. The spin of the alternating layers is antiparallel, which leads to an antiferromagnetic material.

Guo et al [64] performed surface energy calculations for $\alpha-\mathrm{Fe}_{2} \mathrm{O}_{3}$. The authors studied the most important surfaces of hematite: (001)-Fe, (012), (100) and (110), of which 


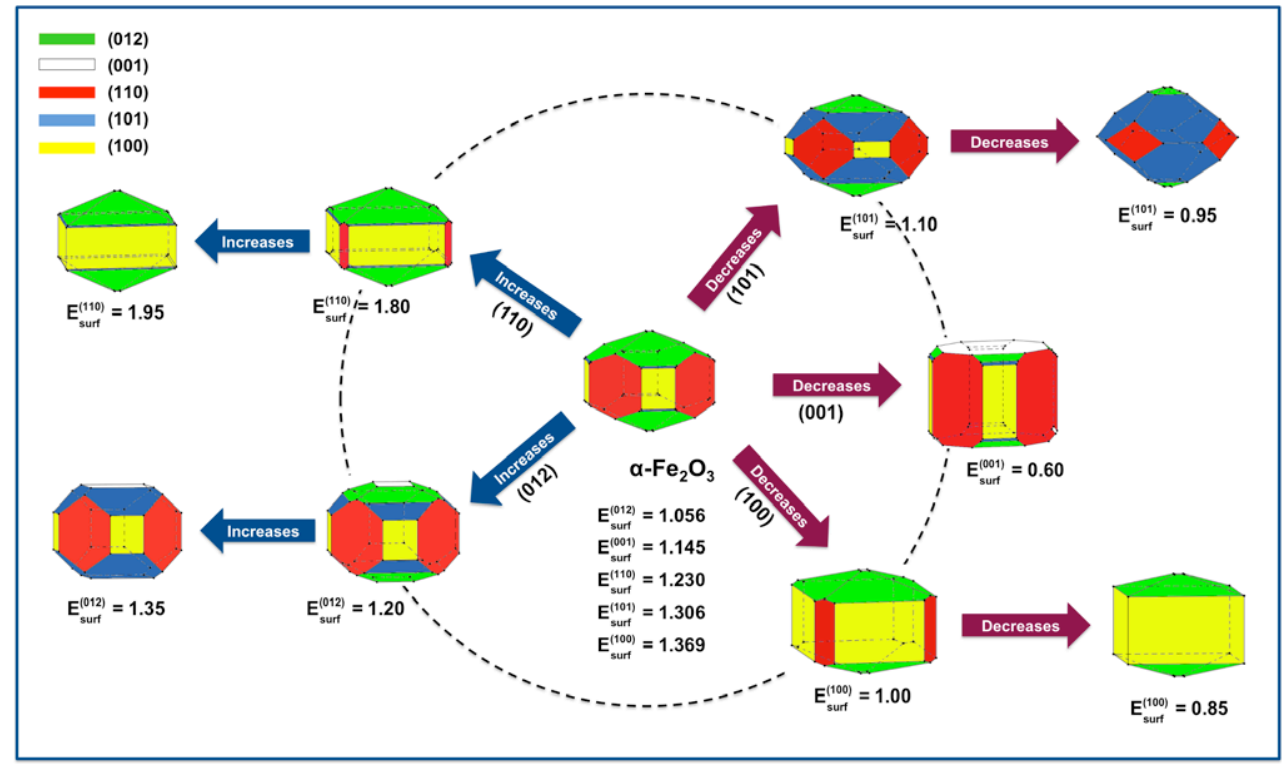

Figure 2. Crystallographic structure and morphologies of $\alpha-\mathrm{Fe}_{2} \mathrm{O}_{3}$ with crystal planes (001), (012), (100), (101) and (1 1 10). Surface energy is in joule per-square meter.

(00 1) was the most extensively studied. The reported surface energies for these slabs and the morphologies generated by Wulff construction are shown in the center of figure 2. Central morphologies of figure 2 seem to be in agreement with scanning electron microscopy images of $\alpha-\mathrm{Fe}_{2} \mathrm{O}_{3}$ particles formed in 5 mol\% octadecylamine (ODA) for $48 \mathrm{~h}$ reported by Liu et al [59]. However, they reported a tetrakaidecahedral morphology increasing ODA to $12 \mathrm{~mol} \%$ and enhancing the appearance of (112), (001) and (-112) facets over the other. The influence in morphology of temperature as well as a mixture EtOH/ $\mathrm{H}_{2} \mathrm{O}$ has been investigated [56] obtaining rhombohedra more or less truncated and cubic morphologies, which fit with some morphologies depicted in figure 2 involving different ratios of (012) and (100) surfaces.

Table 2 shows that the value for $D_{\mathrm{b}}$ index decreases in the order: $(001) / \mathrm{Fe}>(100)>(101)$ $>\left(\begin{array}{lll}0 & 01\end{array}\right) / \mathrm{O}>\left(\begin{array}{lll}0 & 12\end{array}\right)>(110)$, while the surface energy decreases in this order: $(100)>$ $(101)>(110)>(001) / \mathrm{Fe}>(012)>(001) / \mathrm{O}$. Because $\mathrm{H}$ atoms were added to the $(001)-\mathrm{O}$ surface there is a large difference in the order of the (001)-O surface energy compared to the $D_{\mathrm{b}}$ representation. For this reason, the (001)-O surface energy was not used in the Wulff construction to generate the hematite morphology shown in figure 2. From the analysis of the (001)-O surface, it is clear that $\mathrm{H}$ atoms stabilized the under-coordinated $\mathrm{O}$ atoms on the surface, and this decreased both the surface energy and the density of broken bonds. In this system, the $D_{\mathrm{b}}$ values are not consistent with the simulated surface energy order. This can be related to the theoretical methodology used by Guo et al [64] to study the surface energy. That is, the surface model contained surface vacancies that are not fully explained.

\section{3. $\mathrm{In}_{2} \mathrm{O}_{3}$}

Indium oxide $\left(\mathrm{In}_{2} \mathrm{O}_{3}\right)$ is an n-type highly degenerate wide band gap material that has many applications. Indium oxide is used in flat panel displays, photoelectric devices, windshield defrosting layers, heat-reflecting mirrors, high-transparency layers and gas sensor devices 
Table 2. Values of $E_{\text {surf }}$, number of broken bonds, area, and broken bonding density $\left(D_{\mathrm{b}}\right)$ calculated for $\alpha-\mathrm{Fe}_{2} \mathrm{O}_{3}$.

\begin{tabular}{lllll}
\hline \multicolumn{5}{c}{$\alpha-\mathrm{Fe}_{2} \mathrm{O}_{3}$} \\
\hline Surface & $E_{\text {surf }}\left(\mathrm{J} \mathrm{m}^{-2}\right)$ & Broken bonds & Area $\left(\mathrm{nm}^{2}\right)$ & $D_{\mathrm{b}}\left(\mathrm{nm}^{-2}\right)$ \\
\hline$(001)-\mathrm{Fe}$ & 1.145 & 12 & 0.2196 & 54.65 \\
$(012)$ & 1.056 & 8 & 0.2733 & 29.27 \\
$\left(\begin{array}{lll}1 & 0 & 0\end{array}\right)$ & 1.369 & 28 & 0.6923 & 40.44 \\
$\left(\begin{array}{lll}1 & 0 & 1\end{array}\right)$ & 1.306 & 12 & 0.2421 & 49.57 \\
$\left(\begin{array}{lll}1 & 10\end{array}\right)$ & 1.230 & 8 & 0.3997 & 20.01 \\
$(001)-\mathrm{O}$ & 0.782 & 9 & 0.2196 & 40.99 \\
\hline
\end{tabular}

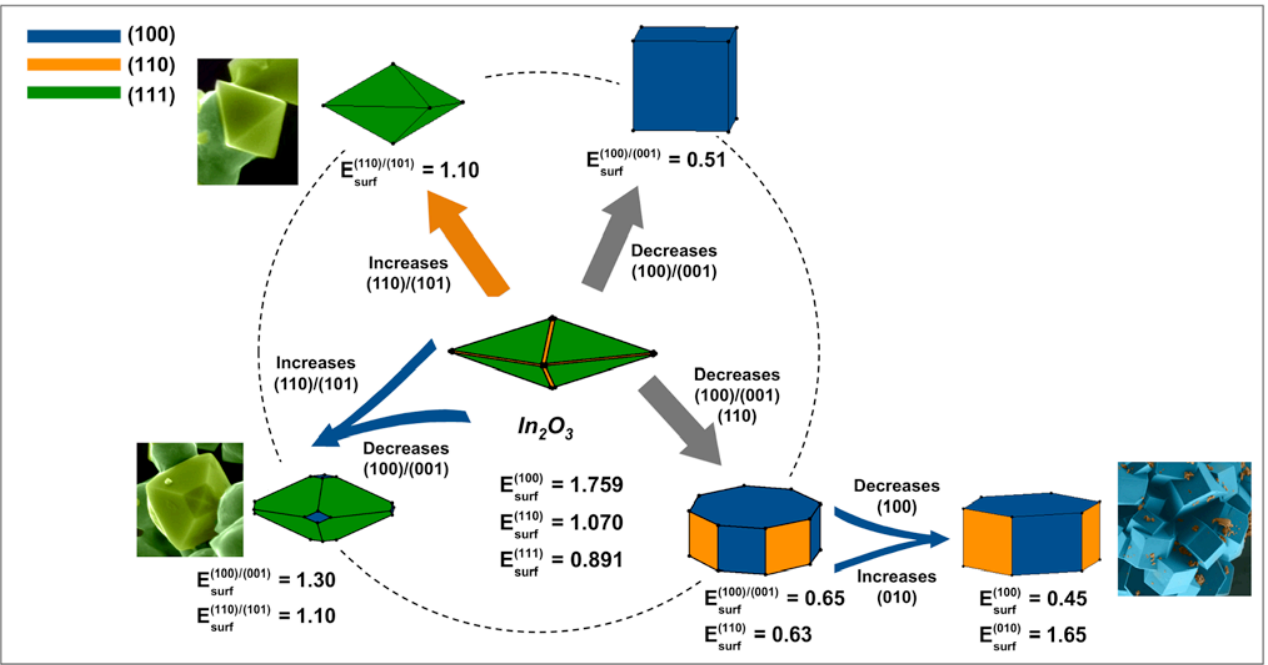

Figure 3. Crystallographic structure and morphologies of $\operatorname{In}_{2} \mathrm{O}_{3}$ with crystal planes (100), (1 1 10) and (111). Surface energy is in joule per-square meter.

[65]. The body-centered cubic polymorph of $\mathrm{In}_{2} \mathrm{O}_{3}$ crystallizes in the space group Ia-3 with eight formula units $(Z=8)$ in the unit cell.

Walsh and Catlow [66] performed surface energy calculations for $\operatorname{In}_{2} \mathrm{O}_{3}$. We have used their surface values to generate the Wulff construction and the morphologies of $\operatorname{In}_{2} \mathrm{O}_{3}$. Figure 3 shows the energies, morphologies and the comparison with experimental results for $\mathrm{In}_{2} \mathrm{O}_{3}$ in our laboratory [67].

According to table 3, the order of stability using the $D_{\mathrm{b}}$ method is $\left(\begin{array}{lll}1 & 1 & 1\end{array}\right)<(110)<(100)$, the same as the theoretical surface energies. Thus, $\mathrm{In}_{2} \mathrm{O}_{3}$ surfaces with higher energies possess the highest amount of unsaturation on the surface.

\section{Conclusions}

It is mandatory to control the morphology of a micro/nanocrystal for for many scientific and technological applications. In this work, we used first principle calculations, based on the Wulff construction model and broken bonding density index, to investigate the effect of surface chemistry on the mechanism of morphology transformation of metal oxides: $\mathrm{Co}_{3} \mathrm{O}_{4}, \alpha-\mathrm{Fe}_{2} \mathrm{O}_{3}$, 
Table 3. Values of $E_{\text {surf }}$, number of broken bonds, area, and broken bonding density $\left(D_{\mathrm{b}}\right)$ calculated for $\mathrm{In}_{2} \mathrm{O}_{3}$.

\begin{tabular}{lllll}
\hline \multicolumn{5}{c}{$\mathrm{In}_{2} \mathrm{O}_{3}$} \\
\hline Surface & $E_{\text {surf }}\left(\mathrm{J} \mathrm{m}^{-2}\right)$ & Broken bonds & Area $\left(\mathrm{nm}^{2}\right)$ & $D_{\mathrm{b}}\left(\mathrm{nm}^{-2}\right)$ \\
\hline$(100)$ & 1.759 & 48 & 1.024 & 46.90 \\
$(110)$ & 1.070 & 24 & 0.7238 & 33.16 \\
$(111)$ & 0.891 & 42 & 1.773 & 23.69 \\
\hline
\end{tabular}

and $\mathrm{In}_{2} \mathrm{O}_{3}$. Using a methodology recently developed by our research group, a detailed configurational analysis of the different faces was performed. A correlation between the broken bonding density $\left(D_{\mathrm{b}}\right)$ and the surface energies was found. The relaxed structures and surface energies were used to obtain a complete array of accessible morphologies. Manipulating the values of surface energy for each face plays a significant role, and it is exemplified in the aforementioned materials.

This method provides an approach with both predictive and explanatory capabilities and the results presented here are an illustration of how first principle calculations can rationalize the mechanisms stabilizing the morphology of micro- and nano-particles at the atomic level. The calculated diagrams relate the crystal growth conditions with the observed morphologies in an attempt to rationalize the morphologies obtained under different conditions. The morphological transformation of $\mathrm{Co}_{3} \mathrm{O}_{4}, \alpha-\mathrm{Fe}_{2} \mathrm{O}_{3}$, and $\mathrm{In}_{2} \mathrm{O}_{3}$ materials revealed by this model was consistent with the Wulff construction.

Our results point out that starting by surface thermodynamics is a helpful approach to predict and assess the morphology transformation of materials and they are very useful in interpreting changes in crystal morphology. By this way, this method allow to understand how tuning the surface can control the shape of micro and nanocrystals synthetically. We expect that our work is beneficial to get a profound understanding of how to achieve shape-controlled materials synthesis than the normal trial and error synthetic procedure.

\section{Acknowledgments}

The authors are grateful to for Prometeo II/2014/022 and ACOMP/2014/270 projects (Generalitat Valenciana), Ministerio de Economía y Competitividad (Spain), CTQ201236253-C03-02, FAPESP (2013/07296-2 and scholarship process 2013/26671-9 and 2012/14468-12014/04350-9), CAPES (process A104/2013 and 99999.002998/2014-09), CNPq INCTMN 573636/2008-7, and the Spanish-Brazilian program (PHB2009-0065-PC) for financially supporting this research.

\section{References}

[1] Mcllroy A et al 2006 Basic Research Needs for Clean and Efficient Combustion of 21st Century Transportation Fuels

[2] Kuang Q, Wang X, Jiang Z, Xie Z and Zheng L 2014 Acc. Chem. Res. 47 308-18

[3] Chen K, Sun C, Song S and Xue D 2014 CrystEngComm. 16 5257-67

[4] Tompsett D A, Parker S C, Bruce P G and Islam M S 2013 Chem. Mater. 25 536-41

[5] Kim Y, Lee H and Kang S 2012 J. Mater. Chem. 22 12874-81

[6] Karim A, Fosse S and Persson K A 2013 Phys. Rev. B 87075322

[7] Eunseok L and Kristin A P 2013 Nanotechnology 24424007

[8] Hörmann N G and Groß A 2014 J. Solid State Electrochem. 18 1401-13 
[9] Li Y et al 2014 Phys. Chem. Chem. Phys. 16 24604-9

[10] Barnard A S 2012 Acc. Chem. Res. 45 1688-97

[11] Barnard A S and Kirkland A I 2008 Chem. Mater. 20 5460-3

[12] Seyed-Razavi A, Snook I K and Barnard A S 2010 J. Mater. Chem. 20 416-21

[13] Gurlo A 2011 Nanoscale 3 154-65

[14] Zasada F et al 2011 J. Phys. Chem. C 115 6423-32

[15] Stroppa D G et al 2011 Chem. - Eur. J. 17 11515-9

[16] Beltrán A, Andrés J, Longo E and Leite E R 2003 Appl. Phys. Lett. 83 635-7

[17] Leite E R, Giraldi T R, Pontes F M, Longo E, Beltrán A and Andrés J 2003 Appl. Phys. Lett. 83 1566-8

[18] Stroppa D G et al 2014 Phys. Chem. Chem. Phys. 16 1089-94

[19] Bomio M R D et al 2013 J. Phys. Chem. C 117 21382-95

[20] Longo V M et al 2011 J. Phys. Chem. C $11520113-9$

[21] Qi K et al 2014 J. Phys. Chem. C 118 23320-7

[22] Piskorz W et al 2012 J. Phys. Chem. C 116 19307-20

[23] Whiteside A, Fisher C A J, Parker S C and Saiful Islam M 2014 Phys. Chem. Chem. Phys. 16 21788-94

[24] Li P et al 2012 Cryst. Growth Des. 12 5042-50

[25] Suleiman I et al 2015 Phys. Chem. Chem. Phys. 17 7038-45

[26] Kanaki E, Gohr S, Mueller C and Paulus B 2015 Surf. Sci. 632 158-63

[27] Barmparis G D, Lodziana Z, Lopez N and Remediakis I N 2015 Beilstein J. Nanotechnol. 6 361-8

[28] Lovette M A, Browning A R, Griffin D W, Sizemore J P, Snyder R C and Doherty M F 2008 Ind. Eng. Chem. Res. 47 9812-33

[29] Chen J, Lim B, Lee E P and Xia Y 2009 Nano Today 4 81-95

[30] Jiang Z-Y, Kuang Q, Xie Z-X and Zheng L-S 2010 Adv. Funct. Mater. 20 3634-45

[31] Lee K, Kim M and Kim H 2010 J. Mater. Chem. 20 3791-8

[32] Grena R et al 2015 J. Phys. Chem. C 119 15618-26

[33] Yang H G et al 2008 Nature 453 638-41

[34] Zasada F, Piskorz W and Sojka Z 2015 J. Phys. Chem. C 119 19180-91

[35] Xie X, Li Y, Liu Z-Q, Haruta M and Shen W 2009 Nature 458 746-9

[36] Andrés J, Gracia L, Gouveia A F, Ferrer M M and Longo E 2015 Nanotechnology 26 405703-13

[37] Roca R A et al 2015 Catal. Sci. Technol. 5 4091-107

[38] Botelho G, Andres J, Gracia L, Matos L S and Longo E 2015 Chem PhusChem.

[39] Fabbro M T et al 2015 Sci. Technol. Adv. Mater. (In press)

[40] Wulff G 1901 Z. Kristallogr. 34 449-530

[41] Gao Z-Y, Sun W and Hu Y-H 2014 Trans. Nonferr. Met. Soc. 24 2930-7

[42] Mulinari T A, La Porta F A, Andres J, Cilense M, Varela J A and Longo E 2013 CrystEngComm. $157443-9$

[43] Sun H, Ang H M, Tade M O and Wang S 2013 J. Mater. Chem. A 1 14427-42

[44] Yuan C, Zhang L, Hou L, Pang G and Oh W-C 2014 RSC Adv. 4 14408-13

[45] Singh V, Kosa M, Majhi K and Major D T 2014 J. Chem. Theory Comput. 11 64-72

[46] Su D, Dou S and Wang G 2014 Sci. Rep. 45767

[47] Gao R, Zhu J, Xiao X, Hu Z, Liu J and Liu X 2015 J. Phys. Chem. C 119 4516-23

[48] Mu J, Zhang L, Zhao G and Wang Y 2014 Phys. Chem. Chem. Phys. 16 15709-16

[49] Xiao J, Kuang Q, Yang S, Xiao F, Wang S and Guo L 2013 Sci. Rep. 32300

[50] Cao H, Wang G, Zhang L, Liang Y, Zhang S and Zhang X 2006 ChemPhysChem. 7 1897-901

[51] Braun A et al 2012 J. Phys. Chem. C 116 16870-5

[52] Hisatomi T et al 2012 Faraday Discuss. 155 223-32

[53] Sivula K 2013 J. Phys. Chem. Lett. 4 1624-33

[54] McKone J R, Lewis N S and Gray H B 2013 Chem. Mater. 26 407-14

[55] Mayer M T, Lin Y, Yuan G and Wang D 2013 Acc. Chem. Res. 46 1558-66

[56] Li X, Lei Y, Li X, Song S, Wang C and Zhang H 2011 Solid State Sci. 13 2129-36

[57] Lv B, Xu Y, Wu D and Sun Y 2011 CrystEngComm. 13 7293-98

[58] Wang W, Howe J Y and Gu B 2008 J. Phys. Chem. C 112 9203-8

[59] Liu Z, Lv B, Wu D and Sun Y 2012 Particuology 10 456-61

[60] Liu Z, Lv B, Wu D, Sun Y and Xu Y 2013 Particuology 11 327-33

[61] Chakrabarty S and Chatterjee K 2013 J. Cryst. Growth 381 107-13

[62] Lützenkirchen J et al 2015 Faraday Discuss. 180 55-79 
[63] Liang C et al 2015 New J. Chem. 39 2651-6

[64] Guo H and Barnard A S 2011 J. Mater. Chem. 21 11566-77

[65] Mehta B R and Singh V N 2005 Pramana - J. Phys. 65 949-58

[66] Walsh A and Catlow C R A 2010 J. Mater. Chem. 20 10438-44

[67] Motta F V, Lima R C, Marques A P A, Leite E R, Varela J A and Longo E 2010 Mater. Res. Bull. 45 1703-6 


\section{QUERIES}

Page 1

AQ1

Please be aware that the colour figures in this article will only appear in colour in the online version. If you require colour in the printed journal and have not previously arranged it, please contact the Production Editor now.

\section{Page 8}

AQ2

Please check the details for any journal references that do not have a link as they may contain some incorrect information.

\section{Page 9}

AQ3

Please provide the volume and page/article number for references [38, 39]. 